\title{
Rare Tumors: An Appeal for Justice
}

\author{
T. Patrick Hill ${ }^{*}, 1,2,3$
}

${ }^{I}$ Edward J. Bloustein School of Planning and Public Policy Rutgers, The State University of New Jersey, NJ 089030019, USA ${ }^{2}$ The Cancer Institute of New Jersey; ${ }^{3}$ The Neonatology Division, UMDNJ-Robert Wood Johnson Medical School, New Jersey, NJ 08903-0019, USA

\begin{abstract}
While cancers with 40,000 or fewer diagnoses a year are considered rare, they make up about $25 \%$ of cancer mortalities. Despite this, rare cancers remain largely ignored by investigators because of insufficient research funding. Their neglect has been justified in the belief that a focus on common tumors will yield benefits for all tumors, including rare tumors. This however has not happened. One solution proposed to address this problem is to mobilize those diagnosed with rare tumors to advocate for research in rare tumors. But is it fair to place a burden of self-advocacy on some cancer patients but not on others? A better solution, proposed here, invokes a theory of justice developed by John Rawls, and offers an alternative statement of the ethical basis for involving human subjects in research and suggestions for restructuring the cancer research enterprise itself.
\end{abstract}

Keywords: Common tumors, rare tumors, justice.

In her recent paper [1] discussing research on "rare" tumors, Amy Marcus asserted that the war on cancer cannot be a war only on behalf of certain patients or certain tumors. The only acceptable goal is a basic knowledge about all cancers. But Marcus' assertion, an ethicist might argue, rests on the assumption that a war confined to certain patients or certain tumors would violate the principle of justice understood as the fair distribution of society's resources to its members.

The data confirm this. According to Marcus, "rare" cancers are those with fewer than 40,000 diagnoses a year. According to the 2009 estimates published by the American Cancer Society (ACS), ovarian at 21,500 diagnoses, brain at 22,070 , stomach at 21,130 , thyroid at 37,200 , and cervical at 11,270 , would qualify as "rare" cancers. Together with the other cancers with fewer than 40,000 diagnoses a year, they make up about $25 \%$ of cancer mortalities. Despite this alarming figure, "rare" cancers remain largely ignored by investigators because research funding is insufficient or worse, unavailable. This neglect, Marcus continues, has been justified in the belief that the focus on common tumors would yield benefits for all cancer patients, whether their cancer is "common" or "rare."

The belief might be plausible were it not for the fact that, again using the ACS estimates for 2009, pancreas at 42,479 diagnoses, leukemia at 44,790, rectum at 40,870 and endometrial at 42,160 , barely avoid the "rare" designation. If anything, these figures reveal the wrongheadedness of setting research priorities on the basis of a distinction between "common" and "rare" tumors that is arrived at by such an arbitrary means. How wrongheaded we can see from what we learned from chronic myelogenous leukemia

*Address correspondence to this author at the Edward J. Bloustein School of Planning and Public Policy Rutgers, The State University of New Jersey, NJ 08903-0019, USA; Tel: 732-530-7969; Fax: 732-932-2253; E-mail: tpatri@rci.rutgers.edu
(CML) when treated with imatinib mesylate. With an estimated 5050 diagnoses in 2009, CML is a decidedly "rare" tumor. Despite that, it is reasonable to say that it was instrumental in our coming to understand the molecular and genetic signaling involved in cancer cells multiplying and surviving. That its success had nothing to do with whether CML is a "common" or "rare" tumor should give pause for thought since the prevailing rationale for research priorities provides little evidence of a transfer of knowledge, learned from "common" tumors, to "rare" tumors. In the absence of any sustained transfer of knowledge, Marcus argues that if we are to make progress in the study of "rare" cancers, it is up to patients with "rare" tumors and their advocacy groups to lead the way.

At first glance this may seem a reasonable strategy. On closer examination, however, it adds further injustice to a well-established practice of benign neglect by placing additional burdens exclusively on patients already burdened with serious disease. Why should patients with a "rare" tumor have to lobby for funding for research on their tumors, while patients with "common" tumors do not? What is the strength of the claim of patients with a "rare" tumor, compared to that of the claim of patients with a "common" tumor, on research resources at the national or the institutional level? Does it come from the rate of tumor incidence, so that the higher the rate, the stronger the claim? In light of the data above, it is hard to conclude otherwise. And it may be thought that, given our limited resources, as a form of economic triage, this is the only economically sustainable course to pursue. But is it also ethically sustainable?

One way to answer this question is to apply a theory of justice, developed by John Rawls [2]. The theory rests on the premise that "Justice is the first virtue of social institutions, as truth is of systems of thought" [3], which, Rawls thinks, may explain the tendency to reform or abolish unjust institutions in the same way that we restate or abandon untrue theories. As he puts it, the only excuse for an erro- 
neous theory is the absence of something better. The only excuse for an injustice is the avoidance of a greater injustice. "Being first virtues of human activities, truth and justice are uncompromising" [4].

With this premise in place, Rawls argues that "Each person possesses an inviolability founded on justice that even the welfare of society as a whole cannot override" [5]. On the face of it, by neglecting in our cancer research enterprise patients with rare tumors, we have endorsed a policy that allows the interests of the cancer community as a whole to override the interests of a sub-set of this community. The consequence is not only injustice. It is also an assault on the inviolability of persons because it compromises the fundamental condition of membership under which, according to Michael Walzer, each of us exists in society. This point is central to Walzer's argument that there is something special about a membership whose overriding objective is "Political community for the sake of provision, provision for the sake of community" with the distinctive feature that "the process works both ways" [6].

In Rawlsian language, this means that society is essentially an enterprise of cooperation among its members for their mutual benefit. The realization of benefit occurs in two ways. The first, by acknowledging members' shared interests "since social cooperation makes possible a better life for all than any one would have if each were to live solely by his own efforts" [7]. The second, by recognizing that membership inevitably occasions competing interests. Aware of the greater benefits resulting from their cooperation, members have a vested interest in the distribution of those benefits, pre-disposed as they are for their own goals to enjoy more rather than less of them [8]. In the tension between cooperation and competition, justice is our way of distributing benefit so that personal inviolability as ultimate interest remains secure. Society, Rawls believes, is organized so as to distribute equally certain primary goods, including health, on the presumption that every rational person would want them for their essential well-being. Any inequalities of distribution are tolerable only if their outcome benefits all members of society.

Here one might argue that this could justify the prevailing policy regarding research on "rare" tumors. The unequal distribution of research resources, favoring patients with "common" tumors in the short term, is intended to bring the benefits achieved to patients with "rare" tumors in the long term. But the argument fails on two counts. First, the inequality and universal benefit are to be simultaneous in the way that the inequality and benefit of our graduated income tax are simultaneous. But the inequality in the distribution of research resources to the disadvantage of patients with "rare" tumors amounts to postponing benefit indefinitely to a population which, as a consequence, represents $25 \%$ of cancer deaths. This is hardly a benefit. Second, as Marcus notes, we are beginning to stratify even "common" tumors. As a result, she insists it is time to focus attention and resources on "rare" tumors with the expectation of finding as many pathways and targets as possible.

Doing this would, unavoidably, entail a re-distribution of research resources, with the likelihood of inequalities asserting themselves in new forms. In order, therefore, to meet the challenge implicit in Rawls' notion of justice, the re-distribution would have to be such that cancer patients in general would find resulting treatment options with their inequalities preferable to those without the inequalities [9]. This will become a real possibility if the re-distribution comes with a restatement of the ethical basis for involving human subjects in research and a re-structuring of the cancer research enterprise itself.

The ethical basis for the conduct of research involving human subjects was laid out in the Belmont Report (hereafter Belmont) published in 1979 by the National Commission for Protection of Human Subjects of Biomedical and Behavioral Research. Three principles - respect for persons, beneficence, and justice - make up this basis. Of the three, justice has been the least well articulated. This may have to do with the way Belmont applied justice as a deterrent against the exploitation of vulnerable populations. The effect has been to restrict the role of justice, when applied to clinical research, to preventing disproportionate burdens being borne by some human subjects without compensating benefit. It is for the most part an application of justice to prevent injustice. Coming after the Tuskegee Syphilis study (1932-72) and the Willowbrook Hepatitis Studies (1950's), for example, the Belmont approach is not unreasonable. At the same time, we should note however that if we continue to apply justice in this restricted fashion, we risk overlooking the more important role for justice which, applied positively, is to achieve justice. Given the disproportionate mortality incidence among patients with "rare" tumors, attributable in some significant degree to benign neglect, the role of justice needs to be expanded so that its application to clinical oncology research can achieve justice, not only prevent injustice. This fuller understanding of the role of justice, combined with the evidence of an emerging stratification of tumors argues persuasively for equal access to clinical research for those specifically diagnosed with "rare" tumors. Indeed, absent equal access, it is hard to see how Belmont's two other principles, respect for persons and beneficence, can influence the conduct of clinical research as Belmont intended.

The re-statement of the ethical basis must then reflect a significant shift towards the positive role of justice to achieve justice as the uncompromising foundation of personal inviolability. With that in place and working on behalf of patients with "rare" tumors, the principles of respect for persons and beneficence become more than hollow aspirations.

In practical terms, however, Rawls' claim that justice is the first virtue of social institutions will go begging unless there is a restructuring of the cancer research enterprise itself that complements the re-statement of the ethical basis for clinical research with its emphasis now on distributive justice. Informing this restructuring should be Marcus' premise that a basic knowledge about all cancers is the only way to benefit all cancer patients. If so, then we should abandon the use of "rare tumor" as scientifically misleading in the way its use has prejudiced our research priorities and the accompanying allocation of research resources to the advantage of some and the distinct disadvantage of others. Having taken this step, the next calls for a thorough makeover of the logistical infrastructure supporting clinical research in a way that enables individual trials to accrue 
patients in sufficient numbers to be able to answer in a timely fashion the scientific question posed by the study. Here, the multi-site study, fostered by the various oncology cooperatives and pharmaceutical companies may provide the model of what now must not only accommodate investigator-initiated studies but also be inclusive of all tumors, regardless of their incidence levels. National, if not international, in its scope, the model would be capable of generating valid scientific outcomes.

There are of course reasons why we conduct clinical research the way we do at present. The protection of intellectual property, corporate profits, and professional advancement are some of the most significant. Each one has merit. But in the face of the institutional restructuring being suggested here along the lines advanced by Rawls and Walzer, each would have to undergo serious re-appraisal. In light of those terms, it is not unreasonable to think that both might remind us that, as a social institution, the cancer research community has presumed to enjoy membership in the larger community solely as condition of political community for the sake of provision from the larger community. But in the face of the challenge to social justice posed by patients with so-called "rare" tumors, it is time for the cancer research community to conduct itself also according to the moral imperative of provision for the sake of community. Justice declares that membership functions on a two-way street and justice is uncompromising.

\section{ACKNOWLEDGEMENTS}

I wish to acknowledge Darlene Gibbon, M.D., a colleague at the Cancer Institute of New Jersey, who suggested my use of ACS figures to illustrate the arbitrariness of the category, rare, when cataloguing certain tumors, and the example of imatinib mesylate (Gleevec) to show that research based on rare tumors provides valuable insights for understanding cancer in general.

\section{REFERENCES}

[1] Marcus AD. To make progress in rare cancers, patients must lead the way. JCO 2009; 2575.

[2] Rawls J. A Theory of Justice. Cambridge, Massachusetts: Harvard University Press, 1994.

[3] Ibid. p. 3, quotation no. 1.

[4] Ibid. p. 4, quotation no. 2.

[5] Ibid. p. 3, quotation no. 3.

[6] Walzer M. Spheres of justice: a defense of pluralism and equality. NY: Basic Books 1983.

[7] Rawls. Ibid. p. 4, quotation no. 4.

[8] Ibid. 5 .

[9] Ibid. p. 64

Received: February, 24, 2010

Revised: May 17, 2010

Accepted: May 25, 2010

(C) T. Patrick Hill; Licensee Bentham Open.

This is an open access article licensed under the terms of the Creative Commons Attribution Non-Commercial License (http://creativecommons.org/licenses/by$\mathrm{nc} / 3.0 /$ ), which permits unrestricted, non-commercial use, distribution and reproduction in any medium, provided the work is properly cited. 